\title{
GAMBARAN PENGETAHUAN PASIEN DM TENTANG TANDA DAN GEJALA HIPOGLIKEMI DI PUSKESMAS 1 DENPASAR TIMUR
}

\author{
Artawan, I.K ${ }^{1^{*}}$, Rahayu, N.M.P2 \\ ${ }^{1,2}$ Stikes Kesdam IX/Udayana \\ *Korespondensi: kadekartawan27@gmail.com
}

\begin{abstract}
Background: Diabetes Mellitus is a significant cause of morbidity and mortality today. The risk of death on diabetes mellitus patients due to its complication is steadily increasing. A low level of knowledge about diabetes mellitus complications influences the behavior and prevention of further complications. A routine blood glucose control is an important prevention of diabetes mellitus complication, especially on patients with insulin therapy. Purpose:This descriptive study aimed to describe the knowledge about signs and symptoms of hypoglycemia among diabetes mellitus patients in the Public Health Centre of I East Denpasar. Methods: This was a descriptive study conducted in the Public Health Centre of I East Denpasar. There were 72 diabetes mellitus patients chosen by the purposive sampling technique that participated in this study. The Knowledge Attitude Practice (KAP) questionnaire employed to collect the participant's knowledge about hypoglycemia. Results: Statistical analysis showed that $69.4 \%, 25 \%$, and $5.5 \%$ of participants were having a moderate, good, and poor level of knowledge, respectively. Conclusion: The majority of diabetes mellitus patients in the Public Health Center of I East Center Denpasar was having a moderate level of knowledge about the signs and symptoms of hypoglycemia (64.9\%).
\end{abstract}

Keywords: Diabetes Mellitu; Hypoglycemia; Knowledge

\begin{abstract}
ABSTRAK
Latar Belakang :. Diabetes Mellitus merupakan salah satu masalah kesehatan utama yang menyebabkan kecacatan dan kematian. Peningkatan angka kematian pada diabetes mellitus disebabkan pasien mengalami komplikasi karena pengetahuan pasien tentang Penyakit DM berdampak pada perilaku dan pola pencegahan komplikasi lanjutan, salah satu upaya penanganan yang dilakukan pasien DM adalah dengan pengendalian kadar glukosa darah secara rutin dan komplikasi Diabetes Mellitus yang menjalani terapi obat khususnya terapi insulin. Tujuan: Untuk mengetahui Gambaran Pengetahuan Pasien DM Tentang Tanda dan Gejala Hipoglikemi di Puskesmas I Denpasar Timur. Metode : Penelitian ini menggunakan metode penelitian deskritif. Tempat penelitian dilaksanakan di Puskesmas 1 Denpasar Timur. Cara pengambilan sampel secara purposive sampling dengan jumlah sampel 72 orang dan cara pengumpulan data dengan pengisian kuesioner KAP (Knowledge Attitude Practice).
\end{abstract}

Jurnal Kesehatan Medika Udayana Vol.07 No.01 April 2021 Page 56 
Hasil : Hasil penelitian ini didapatkan bahwa sebagian besar memiliki tingkat pengetahuan cukup sebesar (69.4\%), Baik (25\%), Kurang (5.5\%). Simpulan : Berdasarkan hasil dari gambaran pengetahuan pasien DM tentang tanda dan gejala hipoglikemi Puskesmas 1 Denpasar Timur memiliki tingkat pengetahuan Cukup sebesar $(69.4 \%)$

\section{Kata Kunci : Diabetes Mellitus; Hipoglikemi; Pengetahuan}

\section{PENDAHULUAN}

Diabetes Mellitus merupakan salah satu masalah kesehatan utama yang menyebabkan kecacatan dan kematian. Peningkatan angka kematian pada Diabetes mellitus salah satunya akibat pasien mengalami hipoglikemia (Suswati,2012). Hipoglikemia merupakan suatu kondisi gula darah di bawah $70 \mathrm{mg} / \mathrm{dl}$ (Haditama \& Mega, 2012). Kondisi Hipoglikemia dapat terjadi akibat ketidakpatuhan dari pasien dalam menjalani terapi insulin. (Wahyuningsih,2013). Umunya penderita diabetes jarang mengenali adanya tanda-tanda hipoglikemia. Padahal kondisi hipoglikemi merupakan suatu kegawatan yang perlu pertolongan segera (Hariono,2014). Kondisi hipoglikemi jika tidak mendapatkan pertolongan dapat menyebabkan pasien tidak sadar, kejang dan kerusakan otak sampai meninggal (Prihatin,2010; Borba, 2016).

Kumar (2017) dalam penelitian tentang epidemiologi hipoglikemia di IGD Rumah Sakit India selatan didapatkan hasil pada tahun 2010 mencapai sekitar 135 juta. Angka kejadian Diabetes Mellitus dengan Hipoglikemi terus meningkat dengan jumlah 220 juta penderita di tahun 2010 dan meningkat 300 juta di tahun 2018. Data hasil studi pendahuluan yang diperoleh dari Dinas Kesehatan Kota Denpasar, Jumlah Kunjungan Tertinggi Penderita DM dengan Hipoglikemi pada tahun 2017 terdapat di Puskesmas I Denpasar Timur dengan jumlah kunjungan 1150 Kunjungan. Tahun 2019 jumlah penderita DM dengan Hipoglikemi yang berusia diatas 40 tahun saja sudah tercatat berjumlah 1361 kunjungan di Puskesmas I Denpasar Timur.

Menurut Waspadji (2015) Proses terjadinya hipoglikemia pada orang DM disebabkan karena kurangnya pengetahuan yang tepat dalam penanganan pertama pada saat terjadinya hipoglikemi. dan juga dalam pemberian insulin setelah makan yang menyebabkan terjadinya hipoglikemi .Pada kondisi normal, setelah makan pankreas 
akan secara otomatis melepaskan hormon insulin dengan kadar yang tepat untuk memindahkan glukosa dalam darah ke dalam sel. Saat glukosa memasuki sel, terjadi penurunan kadar gula darah. hipoglikemi diawali tubuh lemas berkeringat dingin, sampai penurunan kesadaran, oleh karena itu pasien DM perlu mengenali tanda hipoglikemia untuk mendapatkan perawatan yang tepat. Saat terjadi hipoglikemi perawat, pasien atau penderita DM bisa mencegah dengan cara minum air manis atau air yang mengandung kalori. Pasien DM juga disarankan mengatur waktu kebutuhan makan dan membatasi jumlah karbohidrat yang dimakan,dan juga sering memonitor gula darah sehingga dapat mengenali hubungan penurunan tingkat gula drah dengan gejala hipoglikemi.

\section{TUJUAN}

Peneltian ini bertujuan untuk mengetahui gambaran tingkat pengetahuan pasien diabtes tentang tanda dan gejala hipoglikemia di puskesmas denpasar timur. Secara khusus bertujuan untuk mengidentifikasikan karakteristik responden dan identifikasi tingkat pengetahuan penderita diabates.

\section{METODE}

Jenis penelitian adalah peneltian deskriptif dengan pendekatan deskriptif analitik. Penelitian dilakukan pada bulan Juni - Juli 2020 di wilayah kerja Puskesmas Denpasar Timur. Penelitia ini juga sudah mendapatkan ijin dari dinas penanaman modal dan pelayanan terpadu satu pintu dengan no surat 069/664/Izin-C/DISPMPT dan surat ijin dari pemerintah kota denpsar dengan no surat 070/023/DPMPTSP/DPS/20. Populasi penelitian adalah seluruh pasien Diabetes yang datang ke Puskesmas Terpadu Denpasar Timur. Sample yang menjadi responden adalah mereka yang menderita diabetes dan bersedia menjadi responden. Responden diambil dengan teknik purposive sampling. Jumlah responden sebanyak 72 orang. Pengambilan data mengunakan kuisioner dengan instrumen KAP dikembangkan oleh Tri Sunaryo. Data yang digunakan dalam penelitian ini adalah data primer yang diperoleh langsung dari pasien DM pada saat kunjungan Puskesmas. Analisis data dilakukan dengan uji 
deskriptif analitik.

\section{HASIL}

Hasil gambaran tingkat pengetahuan pasien diabetes tentang tanda dan gela hipoglikemia didapatkan gambaran karakterisitik responden menurut Umur, Jenis Kelamin, Pendidikan Terakhir, Pekerjaan dan tingkat pengetahuan sesuai dengan tabel 1 dan 2.

Tabel 1. Gambaran karakteristik Responden.

\begin{tabular}{|c|c|c|}
\hline Karakteristik & Jumlah (n) & Presentase (\%) \\
\hline \multicolumn{3}{|l|}{ Umur } \\
\hline $36-45$ & 4 & $5.6 \%$ \\
\hline $46-55$ & 26 & $36.1 \%$ \\
\hline $56-65$ & 34 & $47.2 \%$ \\
\hline$>65$ & 8 & $11.1 \%$ \\
\hline Total & 72 & 100 \\
\hline \multicolumn{3}{|l|}{ Jenis Kelamin } \\
\hline Laki-Laki & 33 & $45.8 \%$ \\
\hline Perempuan & 39 & $54.2 \%$ \\
\hline Total & 72 & 100 \\
\hline Pendidikan & $\mathrm{f}$ & Persentase (\%) \\
\hline SMP/Sederajat & 18 & $25.0 \%$ \\
\hline Tidak tamat SD & 1 & $1.4 \%$ \\
\hline SD/Sederajat & 13 & $18.1 \%$ \\
\hline SMA/Sederajat & 38 & $52.8 \%$ \\
\hline Perguruan Tinggi & 2 & $2.8 \%$ \\
\hline Total & 72 & 100 \\
\hline Pekerjaan & $f$ & Persentase (\%) \\
\hline PNS/Swasta & 19 & $26.4 \%$ \\
\hline TNI/POLRI & 1 & $1.4 \%$ \\
\hline Wirausaha & 30 & $41.7 \%$ \\
\hline Lain-lain & 22 & $30.6 \%$ \\
\hline Total & 72 & 100 \\
\hline
\end{tabular}

Sumber: Data Primer Penelitian 2020 
Berdasarkan tabel 1 didapatkan data bahwa karakteristik umur responden terbanyak berada pada rentang umur 56-65 tahun sebanyak 34 orang (47.2\%). Karakteristik jenis kelamin paling banyak adalah perempuan sejumlah 39 orang $(54,2 \%)$. Menurut tingkat pendidikan responden sebagian besar berpendidikan SMP /Sederajat 18 orang (25.0\%), Tidak Tamat SD sebanyak 1 orang (1.4\%), SD/Sederajat 13 Orang (18.1\%) SMA/Sederajat 38 Orang dan Perguruan Tinggi 2 (2.8\%). Pekerjaan. Sedangkan berdasarkan karakteristik pekerjaan responden bekerja sebagai Wirausaha sebanyak 30 orang (41.7\%), PNS/Swasta 19 orang (26.4\%), TNI/POLRI 1 orang (1.4\%), dan Lain-Lain 22 orang (30.6\%).

Tabel 2. Tingkat Pengetahuan Pasien DM Tentang Tanda dan Gejala Hipoglikemi

\begin{tabular}{ccc}
\hline Tingkat Pengetahuan & Jumlah (n) & Persentase (\%) \\
\hline Baik & 18 & $25 \%$ \\
Cukup & 50 & $69.4 \%$ \\
Kurang & 4 & $5.5 \%$ \\
\hline Total & 72 & 100
\end{tabular}

Sumber: Data Primer Penelitian 2020

Berdasarkan hasil penelitian yang ditunjukan pada tabel 2 dapat dikatakan paling banyak responden memiliki tingkat pengetahuan Cukup dengan jumlah 50 orang $(69.4 \%)$ dari 72 responden.

\section{PEMBAHASAN}

\section{Gambaran Karakteristik Responden}

Berdasarkan hasil penelitian yang ditunjukan pada tabel 1 bahwa karakteristik responden berdasarkan umur pasien Diabetes mellitus yang kontrol ke Puskesmas 1 Denpasar Timur sebagian besar berumur 57-65 tahun yaitu sebanyak (51.4\%). Umur adalah salah satu faktor yang paling umum yang mempengaruhi individu mengalami diabetes. Faktor resiko meningkat secara signifikan setelah usia 45 tahun dan meningkat secara degeneratif setelah usia 65 tahun. Kondisi diabtes pada umur tersebut terjadi karena orang-orang pada usia ini kurang aktif, berat badan akan bertambah dan massa otot akan berkurang sehingga menyebabkan disfungsi pankreas. Disfungsi pankreas dapat menyebabkan peningkatan kadar gula dalam darah karena tidak 
diproduksinya insulin (D'Adamo, 2012). Hasil ini sejalan dengan penelitian oleh Fitriana (2012) yang menyatakan bahwa proporsi terbesar penderita DM dengan komplikasi berdasarkan umur terdapat pada kelompok umur 51-65 tahun (41.4\%) dan proporsi terkecil pada kelompok umur $\geq 40$ tahun (4.3\%). Penelitian serupa oleh Damayanti (2016) menyatakan bahwa kelompok usia $\geq 45$ tahun mempunyai resiko yang besar untuk mengalami itoleransi glukosa.Umur sangat erat kaitannya dengan terjadinya kenaikan kadar glukosa darah, sehingga semakin meningkat usia maka prevalensi diabetes dan gangguan toleransi glukosa semakin tinggi. Proses menua yang berlangsung setelah usia 30 tahun mengakibatkan perubahan anatomis, fisiologis dan biokimia. yang mempengaruhi kondisi kesehatannya.

Karakteristik responden berdasarkan jenis kelamin sebagian besar pasien Diabetes Mellitus yang menjadi responden pada penelitian ini berjenis kelamin perempuan yaitu sebanyak 39 orang (54.2\%). Menurut Afriwandi (2012) menyatakan bahwa wanita lebih beresiko mengidap diabetes mellitus karena secara fisik wanita memiliki peluang peningkatan indeks masa tubuh yang lebih besar. Sindorm siklus bulanan (Premenstual syndrome), pasca menopause yang membuat distribusi lemak tubuh menjadi mudah terakumulasi akibat proses hormonal tersebut sehingga wanita beresiko menderita diabetes mellitus (Afriwandi, 2012). Hasil penelitian ini sejalan dengan penelitian Sinaga (2013) yang menjelaskan proporsi penderita DM dengan komplikasi tertinggi pada jenis kelamin perempuan (65.0\%). Penelitian yang dilakukan Butarbutar (2012) juga menyebutkan proporsi tertinggi penderita DM adalah perempuan (58.6\%). Hal ini karena banyak perempua yang sudah meniakah dan memiliki anak tidak memperhatikan kesehatan tubuhnya. Selain itu, perempuan juga mengalami menopause setelah umur 45 tahun yang kan mempengaruhi fungsi hormonal tubuhnya.

Hawk (2011) mengemukakan bahwa jenis kelamin merupakan salah satu faktor yang dapat mempengaruhi perilaku kesehatan, termasuk dalam mengatur pola makan. Penelitian yang dilakukan oleh Herianto (2011) tentang gambaran karakteristik pasien diabetes mellitus di poli penyakit dalam RSUD dr. M Yunus Bengkulu menyatakan bahwa jenis kelamin perempuan $56.98 \%$ adalah responden terbanyak dalam peneltian 
tersebut.

Penelitian ini berbanding terbailk dengan penelitian oleh Widowati (2010) dimana karakteristik responden diabetes mellitus adalah laki-laki sebanyak (55.6\%). Penelitian serupa yang berbanding terbalik juga oleh Lisna (2010) bahwa penderita diabetes mellitus lebih banyak pada laki-laki (53.3\%) dibandingkan dengan perempuan (46.7\%). Perilaku kesehatan antara laki-laki dan perempuan dijelaskan oleh Kozier (2010).

Karakteristik responden berdasarkan tingkat pendidikan didapatkan hasil bahwa sebagian besar responden pada penelitian ini memiliki tingkat pendidikan SMA/Sederajat yaitu sebanyak 38 (52.8\%). Beberapa penelitian yang pernah dilakukan menjelaskan bahwa tingkat pendidikan mempunyai pengaruh terhadap kesehatan. Orang yang memiliki tingkat pendidikan tinggi biasanya memiliki tingkat pengetahuan tentang kesehatan sehingga orang akan memiliki kesadaran dalam menjaga kesehatan (Irawan,2010). Orang dengan tingkat pendidikan tinggi biasanya akan memiliki banyak pengetahuan tentang kesehatan, dengan adanya pengetahuan tersebut, orang akan memiliki kesadaran dalam menjaga kesehatannya. Hal ini sejalan dengan peneletian oleh Gibney (2010) menyatakan bahwa semakin tinggi tingkat pendidikan semakin besar kepedulian terhadap kesehatan. Hal tersebut sejalan dengan penelitian yang dialkukan oleh Nirnaya(2015) yang mendapatkan hasil bahwa pekerjaan merupakan salah satu hal yang mempengaruhi pengetahuan penderita diabetes, karena kemungkinan akan mendapatkan pengetahuan dari seminar-seminar yang diikuti dari kemampuan mengguankan internet (Jasper, 2014). Responden dengan pendidikan SMA dan saat ini era infromasi dan teknologi memudahkan masyarakat mengakses inormasi kesehatan. Penderita diabetes lebih banyak dengan pendidikan SMA karena orang tamatan SMA di daerah denpasar banyak bekerja dikantoran dengan gajih pas untuk kehidupan sehingga harus bekerja penuh waktu dan kurang untuk berolahraga.

Hasil penelitian terkait dengan pekerjaaan didapatkan data bahwa sebagian besar responden memiliki pekerjaan Wirausaha 30 orang sebanyak (41.7\%). Pekerjaan juga mempengaruhi resiko diabetes mellitus, masyarakat yang sibuk dengan kegiatan atau pekerjaan sehari-hari akan lebih beresiko terkena diabetes mellitus. Menurut 
Gultom (2012) juga mengatakan bahwa setiap orang yang memiliki jam kerja tinggi dengan jadwal makan dan tidur tidak teratur menjadi faktor dalam meningkatnya penyakit DM, kurang tidur juga dapat menganggu keseimbangan hormon yang mengatur asupan makanan dan keseimbangan energi. Hal ini sejalan dengan peneitian Khairah (2013) menyatakan bahwa mayoritas pekerjaan wiraswasta terbanyak pada penderita diabetes sebanyak (44.8\%). American Diabetes Association (2011) menyatakan bahwa aktivitas fisik memiliki manfaat yang besar karena kadar glukosa dapat terkontrol melalui aktivitas fisik serta mencegah terjadinya komplikasi. Seorang wiraswasta yang tidak dapat menagtur waktu dan aktivitas yang banyak cenderung akan mengalami obesitas dan akhirnya menderia diabetes. Hal ini juga karena ada perubahan habit dari seorang wiraswasta dari segi pola diet dan aktivitasnya.

\section{Gambaran Tingkat Pengetahuan Pasien DM Tentang Tanda dan Gejala Hipoglikemi}

Berdasarkan tabel 2 bahwa sebagian besar responden memiliki tingkatpengetahuan cukup dengan jumlah 50 orang (69.4\%) dari 72 responden. Hal ini sejalan dengan penelitian Jazillah (2016) bahwa dimana sebanyak 22 responden (44.0\%) mempunyai tingkat pengetahuan Cukup. Hal ini dikarenakan kurangnya pendidikan kesehatan dan wawasan masing-masing responden dan sebagainya. Responden yang memiliki pengetahuan yang kurang bisa dikarenakan tidak memahami, dan kurangnya penjelasan yang didapat sehingga informasi yang didapat sangatlah kurang (Nina Rahmadiliyani, 2012).

Penelitian Cannonier (2011) ditemukan bahwa semakin tinggi pendidikan seseorang semakin tinggi pula pengetahuan tentang kesehatan yang dimiliki, namun hal tersebut tidak berlaku pada tingkat pendidikan SMA kebawah. Tingkat pengetahuan kesehatan yang baik dimiliki oleh seseorang yang telah menginjak ke jenjang pendidikan terakhir perguruan tinggi. Teori lain menurut Waspadji (2012) juga menyebutkan bahwa masalah kesehatan dan masalah penyakit tidak semata-mata dari kelainan individu. Kebanyakan penyakit yang diderita individu maupun penyakit yang ada pada umumnya bersumber dari ketidaktahuan dan kesalah pahaman atas berbagai informasi kesehatan yang diterima. Pengetahuan tentang hipoglikemia mempengaruhi kemampuan pasien untuk melakukan selfmanagement. Selain itu, pengetahuan bisa menjadi landasan dalam pengambilan keputusan tentang diet, olah raga, pemantauan glukosa darah, penggunaan obat-obatan, pengendalian berat badan, dan perawatan kaki. Sikap dan kemampuan dalam self management yang baik dan memonitor perilaku gaya hidup sehari hari pasien diabetes dan mengubah kebiasaan lama adalah salah satu upaya dalam mengontrol

Jurnal Kesehatan Medika Udayana Vol.07 No.01 April 2021 Jage 63 
diabetes (Jasper, 2014).

Faktor pemahaman atau pengetahuan mengenai penyakit diabetes dengan prilaku self management seseorang sangat penting untuk diperhatikan oleh para tenaga kesehatan (Sawyer, 2010). Berdasarkan hal tersebut dapat digaris bawahi bahwa tingkat pengetahuan responden cukup karena belum optimalnya pengetahuan tentang hipoglikemia dalam melakukan penatalaksanaan diabetes.

\section{SIMPULAN DAN SARAN}

Berdasarkan hasil penelitian mengenai gambaran pengetahuan pasien DM tentang tanda dan gejala hipoglikemi di Puskesmas 1 Denpasar Timur dapat disimpulkan sebagai berikut : Sebagian besar responden berumur 57-65 tahun sebanyak 37 orang $(51.4 \%)$, Jenis kelamin perempuan 39 orang $(54.2 \%)$, pendidikan terakhir SMA/sederajat 38 orang (52.8\%), pekerjaan wirausaha 30 orang (41.7\%). Hasil perhitungan tingkat pengetahuan pasien DM di Puskesmas 1 Denpasar Timur menunjukkan bahwa sebagian besar responden memiliki tingkat pengetahuan dalam kategori cukup yaitu sebanyak 50 orang (69.4\%). Diharapkan petugas kesehatan senantiasa terus memberikan pendidikan kesehatan pada masyarakat terutama tentang DM untuk lebih meningkatkan pengetahuan masyarakat.

\section{DAFTAR PUSTAKA}

Afriwandi, (2012). Faktor Faktor Penyebab Terjadinya Diabetes Mellitus Di Ruangan Murai Rsud Arifin Ahmad Pekanbaru.

Agung wahyu, Y. J. (2016). Study Fenomenologi Pengalaman Penyandang Diabetes Mellitus Pernah Mengalami Episode Hipoglikemia. Nurseline Journal, 160-172.

Aman, M. (2018). Pengenalan Hipoglikemia Dalam Praktik Sehari-Hari. Yogyakarta.

Bibliography,R. (2018). Kementrian Kesehatan Badan Penelitian Dan Pengembangan Kesehatan

Borba, A. K. (2016). Knowledge and attitude about diabetes self-care. Departamento de, 126

Gibney. M. J., Margetts, B. M., Kearney, J. m., Arab, L. (2010). Gizi Kesehatan Masyarakat. Jakarta : EGC 
Haditama, Mega. (2012). Asuhan Keperawatan Pada Ny.S Dengan Hipoglikemi Pada Pasien Diabetes Mellitus Di Instalasi Gawat Darurat RSUD Surakarta, 1-13

Hestiana, Dita Wahyu.(2017). Faktor-Faktor Yang Berhubungan Dengan Kepatuhan Dalam Pengelolaan Diet Pasien Diabetes Mellitus Tipe 2. Jurnal Of health

H.R,D.H (2012). Mengenai Diabetes Mellitus Pada Orang Dewasa Dan Anak-Anak Dengan Solusi Herbal. Yogyakarta

Irawan, Dedi. (2010). Prevalensi Dan Aktor Resiko Kejadian Diabetes Mellitus Tipe 2 Di Daerah Urban Indonesia (Analisa Data Sekunder Riskesdas 2007). Thesis: Universitas Indonesia.

Perkeni. (2011). Petunjuk Praktis Terapi Insulin Pada Pasien Diabetes Mellitus. Jakarta:PB PERKENI

Ristanto, R. (2015). Pencegahan Hipoglikemi Pada Pasien DM Tipe 2. Jakarta. Nuhamedika.

Rumahorbo, D. H .(2014). Mencegah Diabetes Mellitus Dengan Perubahan Gaya Hidup. Bogor.

Shafiee, G., Mohamadreza M.T.,Mohammad P., \& Bagher L. (2012). Theimportance of Hypoglycemia in diabetic patients. Journal of Diabetes \& Metabolic Disorders.

Shaw,J.E, Sicree, R.A., \& Zimmet, P.Z. (2010). Global estimates of the prevalence of diabetes for 2010 and 2030. Diabetes Research \& Clinical Practice.

Smeltzer\&Bare. (2015). Buku Ajar Keperawatan Medical Bedah, Vol.2. Jakarta: EGC

Sunaryo, Tri. (2014). Kuesioner Tentang Hipoglikemi Di Puskesmas Jember Kemenkes RI.2013. Riset Kesehatan Dasar 2013. Jakarta : Kementrian RI

Sugiyono. (2014). Metodelogi Penelitian Kuantitatif, Kualitatif, Dan R\&D. Bandung : Penerbit Alfabeta

Sutawardana, J. H. (2016). Study Fenomenologi Pengalaman Penyandang Diabetesmellitus Yang Pernah Mengalami Episode Hipoglikemia. Yogyakarta.

Swarjana. (2015). Metodelogi Penelitian Kesehatan. Yogyakarta : CV Andi OFFSET Waspadji. (2015). Proses Terjadinya Hipoglikemi Pada Penderita DM.Jakarta : EGC 
Williams. (2012). Metodelogi Penelitian Kesehatan, Ed : 1. Yogyakarta:Nuhamedi 